\title{
Detecting the Early Genetic Effects of Habitat Degradation in Small Size Remnant Populations of Machilus thunbergii Sieb. et Zucc. (Lauraceae)
}

\author{
Shuntaro Watanabe, ${ }^{1,2}$ Yuko Kaneko, ${ }^{3}$ Yuri Maesako, ${ }^{4}$ and Naohiko Noma ${ }^{2}$ \\ ${ }^{1}$ Field Science Education and Research Center, Kyoto University, Oiwake-cho, Kitashirakawa, Sakyo-ku, Kyoto 606-8502, Japan \\ ${ }^{2}$ The University of Shiga Prefecture, No. 2500, Hassaka-cho, Hikone, Shiga 522-8533, Japan \\ ${ }^{3}$ Toyo University, 5-28-20 Hakusan, Bunkyo-ku, Tokyo 112-8606, Japan \\ ${ }^{4}$ Osaka Sangyo University, Nakagaito, Daito, Osaka 574-8530, Japan \\ Correspondence should be addressed to Yuko Kaneko; kaneko065@toyo.jp
}

Received 16 September 2016; Accepted 5 January 2017; Published 2 February 2017

Academic Editor: Ignacio García-González

Copyright (c) 2017 Shuntaro Watanabe et al. This is an open access article distributed under the Creative Commons Attribution License, which permits unrestricted use, distribution, and reproduction in any medium, provided the original work is properly cited.

\begin{abstract}
Habitat degradation caused by human activities has reduced the sizes of many plant populations worldwide, generally with negative genetic impacts. However, detecting such impacts in tree species is not easy because trees have long life spans. Machilus thunbergii Sieb. et Zucc. (Lauraceae) is a dominant tree species of broad-leaved evergreen forests distributed primarily along the Japanese coast. Inland habitats for this species have become degraded by human activities. To investigate the effects of habitat degradation on genetic structure, we compared the genetic diversities of mature and juvenile trees of five $M$. thunbergii populations around Lake Biwa in Japan. Allelic diversity was influenced by past lineage admixture events, but the effects of forest size were not clear. On the other hand, the inbreeding coefficient of the juvenile stage was higher in small populations, whereas large populations maintained panmictic breeding. Also, the extent of genetic differentiation was greater in juveniles than in mature trees. We detected the early genetic effects of habitat degradation in small, isolated M. thunbergii populations, indicating that habitat degradation increases inbreeding and genetic differentiation between populations.
\end{abstract}

\section{Introduction}

Warm-temperate evergreen forests in East Asia occur primarily at low elevations and feature the dominant genera Machilus (Persea), Castanopsis, Quercus, Lithocarpus, Cinnamomum, and Neolitsea [1]. However, in the main island of Japan, such forests are highly degraded because of human disturbance. Generally, habitat degradation caused by humans has reduced the sizes and increased the spatial isolation of many plant populations worldwide. Small population size and increased isolation can cause genetic erosion, increased genetic divergence via random drift, increased inbreeding, reduced gene flow, disrupted pollination, and increased probability of local extinction [2-4]. Genetic erosion caused by habitat fragmentation can be of immediate concern if genetic changes directly influence individual fitness and the short-term viability of remnant populations. One long-term evolutionary consequence of genetic erosion is limitation of the ability to respond to environmental changes, which is expected to increase the probability of extinction $[2,4]$. Recent meta-analyses suggested that plant species generally exhibit negative genetic responses to habitat fragmentation $[5,6]$. However, detecting the impact of habitat fragmentation on the genetic structures of tree species is not easy [7]. Many tree species may be buffered from the effects of such fragmentation by individual longevity, high intrapopulation genetic diversity, and the potential for long-distance pollen flow. Thus, several earlier studies of trees found no evidence that fragmentation influenced genetic parameters (e.g., $[8,9])$. In addition, any reduction in genetic diversity or increase in the level of inbreeding may not be immediately evident after forest fragmentation because the older trees remaining after 
habitat isolation often have the same extent of genetic diversity as that observed prior to fragmentation [7]. Therefore, assessment of only mature members of a population may yield no information on the contemporary genetic effects of isolation. One possible approach to study of the impact of forest fragmentation on the genetic diversity of tree species is to compare the genetic diversity and structure between predisturbance adult populations and postdisturbance generations cohorts [10]. Such comparisons can reveal whether significant, potentially deleterious genetic changes are occurring in the present generation (e.g., [10-13]).

Lake Biwa is the largest freshwater lake in Japan and is located in the west-central region of the country. The lakeside hosts many coastal plants, including Calystegia soldanella (L.) R. Br. (Convolvulaceae), Vitex trifolia subsp. litoralis Steenis, Lathyrus japonicus Willd. (Leguminosae), Arabidopsis kamchatica subsp. kawasakiana (Makino) K. Shimizu \& Kudoh (Brassicaceae), Raphanus raphanistrum subsp. sativus (L.) Domin, Dianthus japonicus Thunb. (Caryophyllaceae), and Pinus thunbergii Parl. (Pinaceae) [14]. Machilus thunbergii Sieb. et Zucc. (Lauraceae) is a broad-leaved evergreen tree species in warm-temperate forests of Japan and also distributed around Lake Biwa. These populations are important because this species is rarely found inland and regarded as a flagship species around Lake Biwa [15]. However, these $M$. thunbergii populations are heavily degraded because their distribution overlaps areas of human activity [16]. As a result of such disturbance, $M$. thunbergii forests around Lake Biwa now occur almost exclusively around Shinto shrines or on islands in the lake. Therefore, some $M$. thunbergii populations around the lake are expected to exhibit low levels of genetic diversity, high levels of inbreeding, and high extents of genetic differentiation.

The objectives of the present study were to analyze and to assess the effects of habitat degradation on local genetic diversity and differentiation of $M$. thunbergii populations that persist around Lake Biwa. We compared the genetic diversities of mature and juvenile $M$. thunbergii in each population, using seven microsatellite markers and evaluated the extent of genetic divergence among populations.

\section{Materials and Methods}

2.1. Study Species. Machilus thunbergii Sieb. et Zucc. is a representative dominant tree species of warm-temperate evergreen forests in Japan. It is distributed mainly around the sea coast, and over $90 \%$ of all trees are distributed along the shore $[17,18]$. The tree grows to approximately $15 \mathrm{~m}$ and blooms from April to June. Bees, flies, and beetles visit flowers and disperse pollen [19]. Machilus thunbergii is a heterodichogamous species, consisting of two types of protogynous and bisexual flowers at the individual-tree level: a morning female-afternoon male morph and a morning maleafternoon female morph [20]. Seeds generally mature from June to August $[21,22]$ and are dispersed by birds, mainly the brown-eared bulbul (Hypsipetes amaurotis Temminck) and the white-cheeked starling (Sturnus cineraceus Temminck).

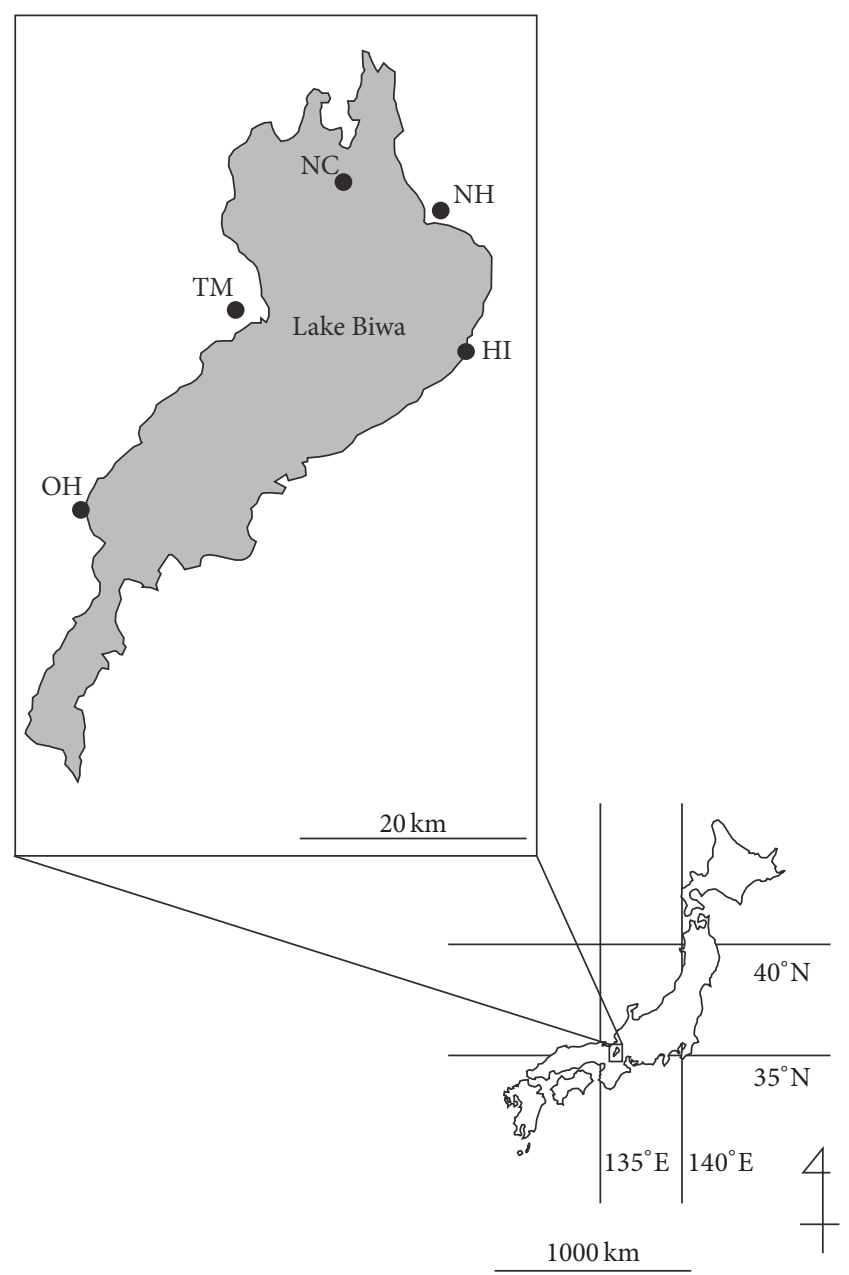

Figure 1: Location of the study sites around Lake Biwa, Japan.

2.2. Study Site. We worked in five warm-temperate evergreen forests around Lake Biwa (Figure 1; Table 1). Lake Biwa is the largest freshwater lake in Japan and is located in the westcentral region of the country.

Chikubushima Island (NC; Nagahama, Shiga, Japan), which is $2 \mathrm{~km}$ away from the shoreline, is uninhabited, and the level of conservation is high. The forest canopy of the island is dominated by evergreen broad-leaved species including $M$. thunbergii, Quercus myrsinifolia Blume, and Ilex integra Thunb. This forest has maintained almost the same primeval state since 15th century. This forest contained more than 100 individuals of $M$. thunbergii. The Hikitari shrine site (NH; Nagahama, Shiga, Japan) is a shrine forest dominated by M. thunbergii, Q. myrsinifolia, and Zelkova serrata (Thunb.) Makino. This forest is surrounded by agricultural area and highly fragmented. This forest contained 15 individuals of $M$. thunbergii. The Inukami River site (HI; Hikone, Shiga, Japan) is a riverside forest located at the outlet of the Inukami River and has a canopy dominated by $M$. thunbergii, Aphananthe aspera (Thunb.) Plach., Quercus aliena Blume, and Celtis sinensis Pers. Area of this forest is decreasing since 1960s owing to river improvement but relatively large size forest 
TABLE 1: Location and size of each M. thunbergii study site.

\begin{tabular}{lccccc}
\hline Study site & Locality & Abbreviation & Latitude & Longitude & Forest area (ha) \\
\hline Hassho-shrine & Otsu, Shiga & $\mathrm{OH}$ & $35^{\circ} 10^{\prime} \mathrm{N}$ & $135^{\circ} 54^{\prime} \mathrm{E}$ & 1.46 \\
Myounji-temple & Takashima, Shiga & $\mathrm{TM}$ & $35^{\circ} 19^{\prime} \mathrm{N}$ & $136^{\circ} 04^{\prime} \mathrm{E}$ & 0.13 \\
Chikubushima-island & Nagahama, Shiga & $\mathrm{NC}$ & $35^{\circ} 25^{\prime} \mathrm{N}$ & $136^{\circ} 08^{\prime} \mathrm{E}$ & 14.17 \\
Hikitari-shrine & Nagahama, Shiga & $\mathrm{NH}$ & $35^{\circ} 26^{\prime} \mathrm{N}$ & $136^{\circ} 12^{\prime} \mathrm{E}$ & 0.88 \\
Inukami-river & Hikone, Shiga & $\mathrm{HI}$ & $35^{\circ} 15^{\prime} \mathrm{N}$ & $136^{\circ} 13^{\prime} \mathrm{E}$ & 9.41 \\
\hline
\end{tabular}

still maintained. This forest contained about 60 individuals of $M$. thunbergii. The Hassho shrine site $(\mathrm{OH}$; Otsu, Shiga, Japan) is another shrine forest, with a canopy dominated by M. thunbergii, Castanopsis cuspidata (Thunb.) Schottky, and Cryptomeria japonica (Thunb. ex L.f.) D. Don. This forest is surrounded by urban area and highly fragmented. This forest contained about 24 individuals of $M$. thunbergii.

The Myounji temple site (TM; Takashima, Shiga, Japan) is a temple forest with a canopy dominated by $M$. thunbergii, C. cuspidata, Q. myrsinifolia, and Z. serrata. This forest is surrounded by paddy fields and highly fragmented. This forest contained 9 individuals of $M$. thunbergii. In this paper, we used areas of forest (ha) as an indicator of population size because we could not evaluate exactly the number of individuals in $\mathrm{HI}$ and $\mathrm{NC}$ population.

2.3. Sample Collection. We collected leaf of mature M. thunbergii trees. The average sample size per population was 29 (range: 9-55), and 147 individual trees were sampled in total. In this study, a mature tree was defined as an individual $>130 \mathrm{~cm}$ in height and $>5 \mathrm{~cm}$ in diameter at breast height. Samples from mature trees were randomly collected at HI and NC, whereas all individuals within a population were sampled at $\mathrm{OH}, \mathrm{TM}$, and $\mathrm{NH}$. In the TM population, we sampled just nine mature trees because there were only nine mature trees.

We also collected leaf samples from juvenile trees, including current-year seedlings and small saplings ( $>1$ year old) to eliminate year-specific effects such as differences in flower or seed mass. The average sample size per population was 34 (range: 18-55), and 172 individuals were sampled in total. Juvenile samples were randomly collected from $\mathrm{HI}$ in 2006, OH in 2010, TM and NH in 2014, and NC in 2015. Leaf samples were stored at $4^{\circ} \mathrm{C}$ with silica gel prior to DNA extraction using a modified cetyltrimethylammonium bromide method [23].

2.4. Microsatellite Typing. Seven loci, corresponding to the microsatellite markers Mt03, Mt04, Mt05, Mt13, Mt14, Mt16, and Mt20 identified by Kaneko et al. [24], were used in the analysis. We scored the genotypes of these microsatellite loci in each DNA sample. We performed PCR amplification using a DNA thermal cycler (Eppendorf, Mastercycler ep gradient S) under the following conditions: initial denaturation at $94^{\circ} \mathrm{C}$ for $9 \mathrm{~min}$, followed by 40 cycles of denaturation at $94^{\circ} \mathrm{C}$ for $30 \mathrm{~s}$ and $1 \mathrm{~min}$ annealing at $72^{\circ} \mathrm{C}$ with a final extension step of $72^{\circ} \mathrm{C}$ for $5 \mathrm{~min}$. The reaction mixtures (5 $\mu \mathrm{l}$ ) contained $2 \mu \mathrm{l}$ PCR Master Mix (Qiagen Multiplex PCR
Buffer, $\mathrm{pH}$ 8.7, consisting of dNTPs, Qiagen HotStarTaq DNA Polymerase, and $\mathrm{MgCl}_{2}$ to a final concentration of $3 \mathrm{mM}$ ) and $10 \mathrm{ng}$ template DNA. The sizes of the PCR products were determined by automated fluorescence scanning using a 3130xl Genetic Analyzer (Applied Biosystems) running the GeneMapper software (Applied Biosystems).

2.5. Genetic Diversity and Genetic Differentiation. For each population, the genetic diversity was evaluated by calculating allelic richness $\left(A_{R} ;[25]\right)$, expected heterozygosity $\left(H_{E}\right)$, and observed heterozygosity $\left(H_{\mathrm{O}}\right)$ values and the fixation index $(F)$. All parameters were calculated using version 2.9 .3 of the FSTAT software [26]. Deviations from Hardy-Weinberg equilibrium (HWE) were assessed using FSTAT. The null alleles affect population parameters which are estimated based on the proportion of heterozygotes. So, we also estimated frequency of null allele for mature and juvenile population of each site and posterior distribution of $F_{\text {(null) }}$ values. $F_{\text {(null) }}$ is inbreeding coefficient which is estimated in consideration of the presence of null alleles. Estimations of $F_{(\text {null) }}$ and the average null allele frequency were conducted under an individual inbreeding model (IIM) using INEst 2.0 (Table 2) [27].

To investigate the relationships between genetic diversity $\left(A_{R}, H_{E}, F\right)$ and forest area (ha), we applied a generalized linear model with an identity link function and Gaussian distribution using the $\mathrm{R} 2.11 .1$ software [28]. Nei's estimates [29] of heterozygosity $\left(H_{S}, H_{T}\right)$ were calculated for multiple loci using FSTAT. To estimate the population size reduction at the mature stage, recent population bottlenecks were evaluated using version 1.2.02 of the BOTTLENECK software [30]. We simulated equilibrium conditions (10000 replications) using both an infinite alleles model (IAM) and a two-phase model (TPM). We used the Wilcoxon signed-rank test to determine if significant excess heterozygosity existed. The TM population was excluded from this analysis due to its small sample size.

To estimate genetic differentiation among populations at both the mature and the juvenile stages, $F_{S T}$ [31], $R_{S T}$ [32], $G_{S T}^{\prime}$ [33] values were calculated. $F_{S T}, R_{S T}, H_{S}, H_{T}$ were computed using FSTAT, and $G_{S T}^{\prime}$ values were computed using GenAlEx $6.5[34]$.

\section{Results}

3.1. Within-Population Genetic Diversity. $A_{R}$ ranged from 2.67 to 4.11 for mature trees and from 2.58 to 4.20 for juveniles (Table 2 ). $A_{R}$ values of mature trees were highest in NC and 
TABLE 2: Genetic diversity of five M. thunbergii populations around Lake Biwa.

\begin{tabular}{lcccccccc}
\hline Site & Population & $N$ & $A_{R}$ & $H_{O}$ & $H_{E}$ & $F$ & $F_{\text {(null) }}$ & Null allele \\
\hline \multirow{2}{*}{$\mathrm{OH}$} & Mature & 24 & 2.67 & 0.60 & 0.51 & -0.17 & 0.02 & 0.02 \\
& Juvenile & 39 & 2.58 & 0.41 & 0.50 & $0.19^{*}$ & 0.05 & 0.12 \\
\multirow{2}{*}{$\mathrm{TM}$} & Mature & 9 & 3.39 & 0.41 & 0.49 & 0.23 & 0.10 & 0.19 \\
& Juvenile & 20 & 3.05 & 0.41 & 0.51 & $0.23^{*}$ & 0.16 & 0.17 \\
$\mathrm{NC}$ & Mature & 55 & 4.11 & 0.58 & 0.62 & 0.08 & 0.05 & 0.08 \\
& Juvenile & 40 & 4.20 & 0.58 & 0.64 & 0.11 & 0.06 & 0.07 \\
$\mathrm{NH}$ & Mature & 15 & 3.84 & 0.61 & 0.62 & 0.06 & 0.04 \\
& Juvenile & 18 & 3.79 & 0.51 & 0.62 & $0.2^{*}$ & 0.16 & 0.09 \\
$\mathrm{HI}$ & Mature & 44 & 3.58 & 0.66 & 0.64 & -0.009 & 0.02 & 0.01 \\
& Juvenile & 55 & 3.43 & 0.52 & 0.58 & 0.12 & 0.07 & 0.06 \\
\hline
\end{tabular}

$N$, number of samples; $A_{R}$, allelic richness (calculated from 14 gene copies); $H_{O}$, observed heterozygosity; $H_{E}$, expected heterozygosity; $F$, inbreeding coefficient for juvenile and mature life stages of $M$. thunbergii; ${ }^{*}$ population significantly deviated from Hardy-Weinberg equilibrium $(P \leq 0.05) ; F_{(\text {null })}$, Bayesian estimated posterior mean value of $F$ in consideration of presence of null alleles; null allele, the average null allele frequency.
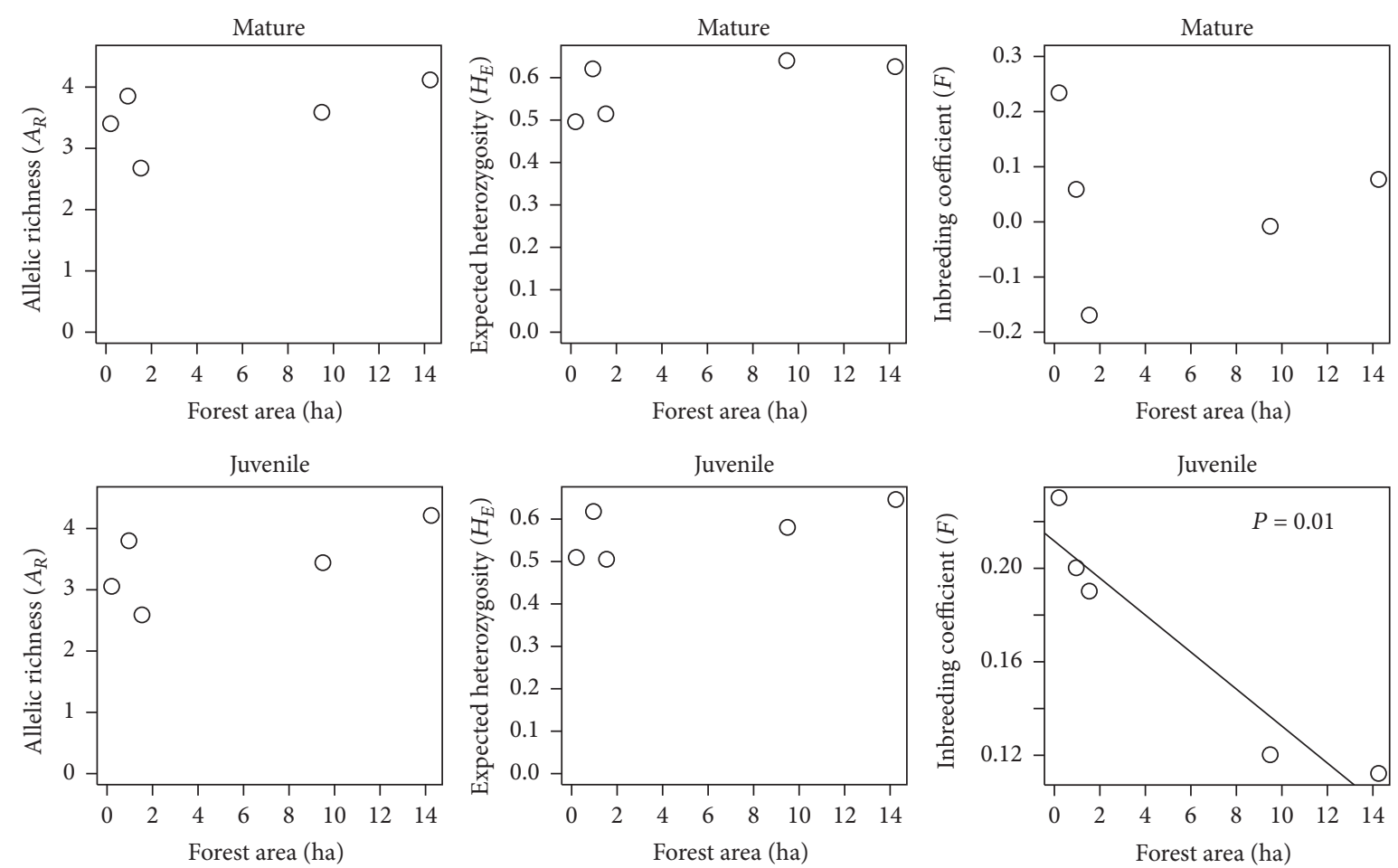

Figure 2: Relationships between the genetic diversity parameters $\left(A_{R}, H_{E}, F\right)$ and forest area in mature and juvenile Machilus thunbergii trees.

lowest in $\mathrm{OH} . H_{O}$ and $H_{E}$ values of mature trees ranged from 0.41 to 0.66 and 0.49 to 0.64 , respectively, and those of juveniles ranged from 0.41 to 0.58 and 0.5 to 0.64 . $F$ values ranged from -0.17 to 0.23 for mature trees and from 0.11 to 0.23 for juveniles. $F$ values of mature trees were highest at $\mathrm{TM}$ and lowest at $\mathrm{OH}$, whereas those of juvenile trees were highest at TM and lowest at NC. No mature tree population deviated significantly from HWE, but deviation from HWE was observed in juvenile populations at $\mathrm{OH}, \mathrm{TM}$, and $\mathrm{NH}$ $(P<0.05)$. The posterior mean values of $F_{(\text {null })}$ ranged from 0.02 to 0.10 for mature trees and from 0.05 to 0.16 for juveniles. Frequency of null allele ranged from 0.01 to 0.19 for mature trees and from 0.04 to 0.17 for juveniles.
Genetic variation within populations, as revealed by $H_{S}$, was higher for mature trees $(0.60)$ than for juveniles $(0.58)$ (Table 3). Values of $H_{T}$ were the same in mature trees and juveniles (0.67). Genetic variation among populations was higher among juvenile compared to adult trees $\left(F_{S T}=0.17\right.$ and $0.13 ; R_{S T}=0.27$ and $0.21 ; G_{S T}^{\prime}=0.35$ and 0.30 , resp., Table 3 ).

3.2. Relationships between Forest Area and Genetic Diversity. Statistical analyses revealed that $F$ values of juvenile trees were significantly negatively correlated with forest area $(P=$ 0.01 , Figure 2). $F$ values of mature trees and $A_{R}$ and $H_{E}$ values of both mature and juvenile trees were not significantly correlated with forest area. 
TABLE 3: Genetic variation within and among populations of $M$. thunbergii.

\begin{tabular}{lccccc}
\hline Populations & $H_{S}$ & $H_{T}$ & $G_{S T}^{\prime}$ & $F_{S T}$ & $R_{S T}$ \\
\hline Among mature trees & 0.60 & 0.67 & 0.30 & 0.13 & 0.21 \\
Among juveniles & 0.58 & 0.67 & 0.35 & 0.17 & 0.27 \\
\hline
\end{tabular}

$H_{S}$, expected genetic diversity within subpopulations; $H_{T}$, total genetic diversity of overall population; $G_{S T}^{\prime}$, genetic differentiation index of Hedrick (2005); $F_{S T}$, genetic differentiation index of Weir and Cockerham (1984); $R_{S T}$, genetic differentiation index of Rousset (1996).

3.3. Bottleneck Test. The BOTTLENECK analysis (using Wilcoxon's signed-rank test) indicated that recent population bottlenecks had occurred. When the Wilcoxon test was run under the IAM and TPM conditions, significant excess heterozygosity was detected in the $\mathrm{OH}, \mathrm{NH}$, and $\mathrm{HI}$ populations (Table 4). When the Sign test was run under the IAM conditions, significant excess heterozygosity was detected in the $\mathrm{NH}$ and $\mathrm{HI}$ populations (Table 4).

\section{Discussion}

4.1. Genetic Diversity. Previous meta-analysis indicated that the number of alleles is generally correlated with population size and rapidly declines with population size reduction [35]. However, in our result, the relationship between $A_{R}$ value and forest area was not significant (Figure 2). We suppose that population history may play an important role in $A_{R}$ value. In the prior study, we have revealed that populations on the western and eastern sides of Lake Biwa have different lineages, and these two lineages were admixed on the northern side of the lake from the phylogenetic analysis of $M$. thunbergii in the Kinki region [36]. Admixture of genetically differentiated populations increases the genetic heterogeneity of the newly established population [37]. In our results, $\mathrm{NH}$ and TM that locate at north side of Lake Biwa maintained relatively high levels of $A_{R}$ value (Table 3) although these population sizes are small. These facts suggest that the effect of past lineage admixture events is grater than that of current population size on $A_{R}$ value for $M$. thunbergii populations around Lake Biwa.

Values of $H_{E}$ were not clearly different among these populations (Table 2). Generally, allelic diversity declines more rapidly than heterozygosity when the population size decreases, and a change in heterozygosity may take several generations to become apparent [2,7]. Aguilar et al. [5] reported significant correlations between the number of generations and the extent of reduction of $H_{E}$. We suspect that because the reduction in population size of $M$. thunbergii around Lake Biwa occurred recently, values of $H_{E}$ reflect the situation before the population size declined. Bottleneck testing supported this speculation and demonstrated significant excess heterozygosity in the $\mathrm{OH}, \mathrm{NH}$, and $\mathrm{HI}$ populations (Table 4, TM population was not analyzed). Bottleneck testing assumes that the reduction of allele number is faster than that of $H_{E}$ [38], and it is effective for assessing recently experienced population size reduction [30]. Thus, our results indicate that the NC population has not experienced recent population size reduction and maintained current population size for a long time, whereas the $\mathrm{OH}, \mathrm{NH}$, and $\mathrm{HI}$ populations experienced a population reduction within the past few generations.

4.2. Inbreeding Coefficient. Our analyses indicated that HWE is maintained in all populations at the mature stage (Table 2), although the statistical significance of the trend in the TM population needs further consideration owing to the small population size. Selection against homozygotes during recruitment could have affected the maintenance of HWE at the mature stage, as tree species generally experience high levels of inbreeding depression early in the life cycle [39]. Machilus thunbergii is a heterodichogamous tree, and this breeding system promotes outcrossing and regulates selfing [20]. The magnitude of inbreeding depression is strong in naturally outbreeding species [40], and the effects of inbreeding depression occur successively at different developmental stages, suggesting reduced levels of inbreeding at later stages due to enhanced mortality caused by inbreeding depression. Thus, selective death of homozygote individuals during growth from the juvenile to the mature stage may have reduced $F$ values of mature trees.

We detected significant deviation from HWE at the juvenile stage in small and disturbed populations $(\mathrm{OH}, \mathrm{TM}$, and $\mathrm{NH}$ ) and maintenance of HWE in relatively large populations (HI and NC; Table 2). In addition, $F$ values of the juvenile stage were significantly correlated with forest area (Figure 2). The most likely explanation for these results is that human exploitation and habitat degradation have reduced the effective population size of adult trees in remnant populations, thus decreasing pollen availability and increasing the level of either self-fertilization or biparental inbreeding in the small, disturbed populations. Some previous researches indicate habitat degradation increases mating with relatives and genetic differentiation of future generations [7, 41-43]. On the other hand, result of $F_{\text {(null) }}$ and frequency of null allele indicate some populations contain substantial proportion of null alleles and this also contributed to the excessive homozygosity. Thus, the values of $F$ of TM and $\mathrm{OH}$ population need further consideration.

Pollen flow among $M$. thunbergii trees occurs primarily within $200 \mathrm{~m}$ (Watanabe et al., unpublished data). In addition, insect pollinators often stay within a habitat fragment, rather than moving among fragments (e.g., [44, 45]). Moreover, habitat degradation has a strong influence on animal pollinators because it affects their population size and foraging behavior [46].

In this study, we were not able to evaluate contemporary gene flow, but results of inbreeding coefficient suggest that the chance of outside gene flow of $M$. thunbergii is possibly diminished by forest degradation in the $\mathrm{OH}, \mathrm{TM}$, and $\mathrm{NH}$ populations, whereas panmictic breeding is maintained in relatively large populations such as NC.

The genetic differentiation index values may also reflect an increase of inbreeding at the juvenile stage in these populations. The values were higher among juveniles than among mature trees (Table 3 ). When contemporary gene flow is restricted by habitat degradation, we would expect to find 
TABLE 4: Probability of a bottleneck estimated using the program BOTTLENECK.

\begin{tabular}{|c|c|c|c|c|}
\hline \multirow{2}{*}{ Population } & \multicolumn{2}{|c|}{ Sign } & \multicolumn{2}{|c|}{ Wilcoxon } \\
\hline & IAM & TPM & IAM & TPM \\
\hline $\mathrm{OH}$ & 0.069 & 0.089 & $0.008^{*}$ & $0.027^{*}$ \\
\hline TM & NA & NA & NA & NA \\
\hline $\mathrm{NC}$ & 0.579 & 0.105 & 0.188 & 0.766 \\
\hline $\mathrm{NH}$ & $0.018^{*}$ & 0.403 & $0.004^{*}$ & $0.039^{*}$ \\
\hline HI & $0.015^{*}$ & 0.122 & $0.004^{*}$ & $0.008^{*}$ \\
\hline
\end{tabular}

The probabilities of significant heterozygosity excess (evidence of bottleneck) for two-tailed Sign and Wilcoxon tests under the IAM and the TPM are marked with an asterisk $\left({ }^{*} P<0.05\right)$. NA, population that was not analyzed.

greater differentiation between seedlings (which are experiencing contemporary, limited gene flow) compared to adults (which experienced historic gene flow).

4.3. Conclusions. Our data suggest that the patterns of allelic diversity were more influenced by the past lineage admixture events than by the current population sizes for $M$. thunbergii populations around Lake Biwa. The extent of inbreeding at the juvenile stage was influenced by population size, and panmictic breeding was maintained in a large population. Our findings suggest that a recent population size decline will modify the mating pattern and increase inbreeding in these M. thunbergii populations.

\section{Competing Interests}

The authors declare that there is no conflict of interests regarding the publication of this paper.

\section{Acknowledgments}

This research was supported by a Grant-in-Aid for Scientific Research (nos. 25340115, 15H04418) from the Ministry of Education, Culture, Sports, Science and Technology, Japan.

\section{References}

[1] T. Kira, "Forest ecosystems of east and southeast Asia in a global perspective," Ecological Research, vol. 6, no. 2, pp. 185-200, 1991.

[2] A. Young, T. Boyle, and T. Brown, "The population genetic consequences of habitat fragmentation for plants," Trends in Ecology and Evolution, vol. 11, no. 10, pp. 413-418, 1996.

[3] R. Lande, "Anthropogenic, ecological and genetic factors in extinction and conservation," Researches on Population Ecology, vol. 40, no. 3, pp. 259-269, 1998.

[4] J. G. B. Oostermeijer, S. H. Luijten, and J. C. M. den Nijs, "Integrating demographic and genetic approaches in plant conservation," Biological Conservation, vol. 113, no. 3, pp. 389-398, 2003.

[5] R. Aguilar, M. Quesada, L. Ashworth, Y. Herrerias-Diego, and J. Lobo, "Genetic consequences of habitat fragmentation in plant populations: susceptible signals in plant traits and methodological approaches," Molecular Ecology, vol. 17, no. 24, pp. 5177-5188, 2008.

[6] G. Vranckx, H. Jacquemyn, B. Muys, and O. Honnay, "MetaAnalysis of Susceptibility of Woody Plants to Loss of Genetic
Diversity through Habitat Fragmentation," Conservation Biology, vol. 26, no. 2, pp. 228-237, 2012.

[7] A. J. Lowe, D. Boshier, M. Ward, C. F. E. Bacles, and C. Navarro, "Genetic resource impacts of habitat loss and degradation; reconciling empirical evidence and predicted theory for neotropical trees," Heredity, vol. 95, no. 4, pp. 255-273, 2005.

[8] R. G. Collevatti, D. Grattapaglia, and J. D. Hay, "Population genetic structure of the endangered tropical tree species Caryocar brasiliense, based on variability at microsatellite loci," Molecular Ecology, vol. 10, no. 2, pp. 349-356, 2001.

[9] M. R. Lemes, R. Gribel, J. Proctor, and D. Grattapaglia, "Population genetic structure of mahogany (Swietenia macrophylla King, Meliaceae) across the Brazilian Amazon, based on variation at microsatellite loci: implications for conservation," Molecular Ecology, vol. 12, no. 11, pp. 2875-2883, 2003.

[10] C. J. Kettle, P. M. Hollingsworth, T. Jaffré, B. Moran, and R. A. Ennos, "Identifying the early genetic consequences of habitat degradation in a highly threatened tropical conifer, Araucaria nemorosa Laubenfels," Molecular Ecology, vol. 16, no. 17, pp. 3581-3591, 2007.

[11] S. Dayanandan, J. Dole, K. Bawa, and R. Kesseli, "Population structure delineated with microsatellite markers in fragmented populations of a tropical tree, Carapa guianensis (Meliaceae)," Molecular Ecology, vol. 8, no. 10, pp. 1585-1592, 1999.

[12] J. L. Hamrick, "Response of forest trees to global environmental changes," Forest Ecology and Management, vol. 197, no. 1-3, pp. 323-335, 2004.

[13] J. V. M. Bittencourt and A. M. Sebbenn, "Genetic effects of forest fragmentation in high-density Araucaria angustifolia populations in Southern Brazil," Tree Genetics and Genomes, vol. 5, no. 4, pp. 573-582, 2009.

[14] S. Kitamura, "Phytogeography of Shiga Prefecture," in Flora of Shiga Prefecture, S. Kitamura, Ed., p. Hoikusha, 1968 (Japanese).

[15] Y. Maesako, N. Noma, Y. Kaneko, M. Yokogawa, S. Watanabe, and Y. Azuma, "Necessity of biodiversity conservation of the Persea thunbergii forest in the Inukami River basin, Shiga Prefecture," Bulletin of Kansai Organization for Nature Conservation, vol. 34, no. 2, pp. 165-179, 2012 (Japanese).

[16] Y. Maesako, T. Fujiwaki, and Y. Kaneko, "Present distribution and regional vegetation of the Persea thunbergii population in western river basins of Lake Biwa, Shiga Prefecture, central Japan," Osaka Sangyo University Journal of Human Environment Study, no. 8, pp. 39-55, 2009 (Japanese).

[17] T. Hattori and S. Nakanishi, "On the distributional limits of the lucidophyllous forest in the Japanese Archipelago," The Botanical Magazine Tokyo, vol. 98, no. 4, pp. 317-333, 1985.

[18] T. Hattori, "Synecological study on Persea thunbergii type forest: geographical distribution and habitat conditions of Persea 
thunbergii forest," Japanese Journal of Ecology, vol. 42, no. 3, pp. 215-230, 1992.

[19] T. Yumoto, "Pollination systems in a warm temperate evergreen broad-leaved forest on Yaku Island," Ecological Research, vol. 2, no. 2, pp. 133-145, 1987.

[20] S. Watanabe, N. Noma, and T. Nishida, "Flowering phenology and mating success of the heterodichogamous tree Machilus thunbergii Sieb. et Zucc. (Lauraceae)," Plant Species Biology, vol. 31, no. 1, pp. 29-37, 2016.

[21] H. Tagawa, "An investigation of initial regeneration in an evergreen broadleaved forest of MINAMATA special research area of IBP. I. Juvenile production and the distribution of two dominant species," Report from EBINO Biology Lab Kyushu University, vol. 1, no. 1, pp. 73-80, 1973.

[22] N. Noma and T. Yumoto, "Fruiting phenology of animaldispersed plants in response to winter migration of frugivores in a warm temperate forest on Yakushima Island, Japan," Ecological Research, vol. 12, no. 2, pp. 119-129, 1997.

[23] B. Milligan, "Plant DNA isolation," in Molecular Genetic Analysis of Populations: A Practical Approach, IRL Press, 1992.

[24] Y. Kaneko, C. Lian, S. Watanabe, K.-I. Shimatani, H. Sakio, and N. Noma, "Development of microsatellites in Machilus thunbergii (Lauraceae), a warm-temperate coastal tree species in Japan," American Journal of Botany, vol. 99, no. 7, pp. e265-e267, 2012.

[25] A. El Mousadik and R. J. Petit, "High level of genetic differentiation for allelic richness among populations of the argan tree [Argania spinosa (L.) Skeels] endemic to Morocco," Theoretical and Applied Genetics, vol. 92, no. 7, pp. 832-839, 1996.

[26] J. Goudet, "FSTAT (version 1.2): a computer program to calculate F-statistics," Journal of Heredity, vol. 6, no. 6, pp. 485-486, 1995.

[27] I. J. Chybicki and J. Burczyk, "Simultaneous estimation of null alleles and inbreeding coefficients," Journal of Heredity, vol. 100, no. 1, pp. 106-113, 2009.

[28] R Development Core Team, R: A Language and Environment for Statistical Computing, R Foundation for Statistical Computing, Vienna, Austria, 2010.

[29] M. Nei, Molecular Evolutionary Genetics, Columbia University Press, 1987.

[30] S. Piry, G. Luikart, and J.-M. Cornuet, "BOTTLENECK: a computer program for detecting recent reductions in the effective population size using allele frequency data," Journal of Heredity, vol. 90, no. 4, pp. 502-503, 1999.

[31] B. S. Weir and C. C. Cockerham, "Estimating F-statistics for the analysis of population structure," Evolution, vol. 38, no. 6, pp. 1358-1370, 1984.

[32] F. Rousset, "Equilibrium values of measures of population subdivision for stepwise mutation processes," Genetics, vol. 142, no. 4, pp. 1357-1362, 1996.

[33] P. W. Hedrick, "A standardized genetic differentiation measure," Evolution, vol. 59, no. 8, pp. 1633-1638, 2005.

[34] R. Peakall and P. E. Smouse, "GenALEx 6.5: genetic analysis in Excel. Population genetic software for teaching and research-an update, Bioinformatics, vol. 28, no. 19, pp. 2537-2539, 2012.

[35] R. Leimu, P. Mutikainen, J. Koricheva, and M. Fischer, "How general are positive relationships between plant population size, fitness and genetic variation?" Journal of Ecology, vol. 94, no. 5, pp. 942-952, 2006.

[36] S. Watanabe, Y. Kaneko, Y. Maesako, and N. Noma, "Range expansion and lineage admixture of the Japanese evergreen tree
Machilus thunbergii in central Japan," Journal of Plant Research, vol. 127, no. 6, pp. 709-720, 2014.

[37] B. Comps, D. Gömöry, J. Letouzey, B. Thiébaut, and R. J. Petit, "Diverging trends between heterozygosity and allelic richness during postglacial colonization in the European beech," Genetics, vol. 157, no. 1, pp. 389-397, 2001.

[38] T. Maruyama and P. A. Fuerst, "Population bottlenecks and nonequilibrium models in population genetics. II. Number of alleles in a small population that was formed by a recent bottleneck," Genetics, vol. 111, no. 3, pp. 675-689, 1985.

[39] K. M. Hufford and J. L. Hamrick, "Viability selection at three early life stages of the tropical tree, Platypodium elegans(Fabaceae, Papilionoideae)," Evolution, vol. 57, no. 3, pp. 518-526, 2003.

[40] B. C. Husband and D. W. Schemske, "Evolution of the magnitude and timing of inbreeding depression in plants," Evolution, vol. 50, no. 1, pp. 54-70, 1996.

[41] P. D. Rymer, M. Sandiford, S. A. Harris, M. R. Billingham, and D. H. Boshier, "Remnant Pachira quinata pasture trees have greater opportunities to self and suffer reduced reproductive success due to inbreeding depression," Heredity, vol. 115, no. 2, pp. 115124, 2015.

[42] R. O. Manoel, P. F. Alves, C. L. Dourado et al., "Contemporary pollen flow, mating patterns and effective population size inferred from paternity analysis in a small fragmented population of the Neotropical tree Copaifera langsdorffi Desf. (LeguminosaeCaesalpinioideae)," Conservation Genetics, vol.13, no. 3, pp. 613623, 2012.

[43] E. V. Tambarussi, D. Boshier, R. Vencovsky, M. L. M. Freitas, and A. M. Sebbenn, "Paternity analysis reveals significant isolation and near neighbor pollen dispersal in small Cariniana legalis Mart. Kuntze populations in the Brazilian Atlantic Forest," Ecology and Evolution, vol. 5, no. 23, pp. 5588-5600, 2015.

[44] R. K. Didham, J. Ghazoul, N. E. Stork, and A. J. Davis, "Insects in fragmented forests: a functional approach," Trends in Ecology \& Evolution, vol. 11, no. 6, pp. 255-260, 1996.

[45] M. Goverde, K. Schweizer, B. Baur, and A. Erhardt, "Smallscale habitat fragmentation effects on pollinator behaviour: experimental evidence from the bumblebee Bombus veteranus on calcareous grasslands," Biological Conservation, vol. 104, no. 3, pp. 293-299, 2002.

[46] L. Ashworth, R. Aguilar, L. Galetto, and M. A. Aizen, "Why do pollination generalist and specialist plant species show similar reproductive susceptibility to habitat fragmentation?" Journal of Ecology, vol. 92, no. 4, pp. 717-719, 2004. 

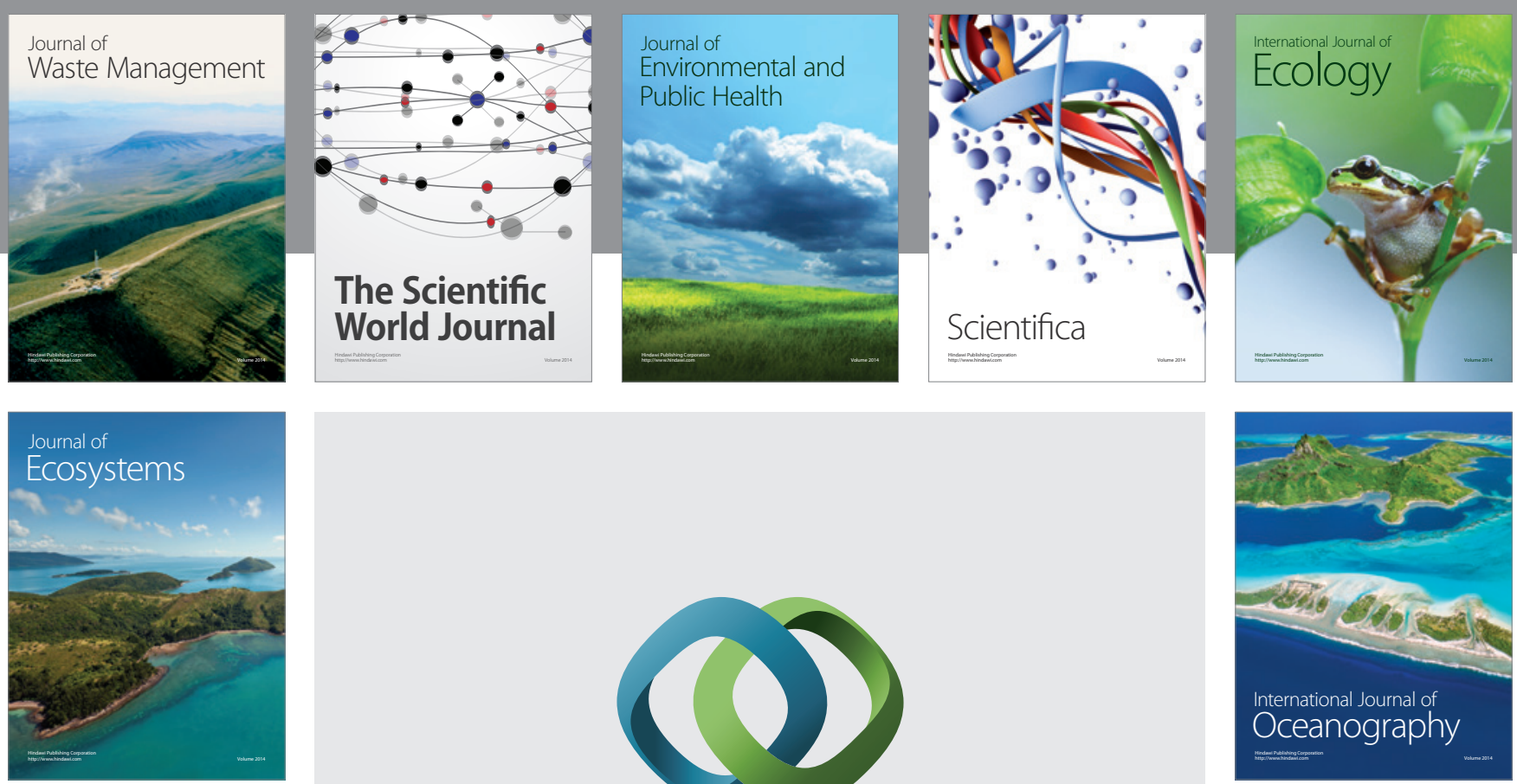

The Scientific World Journal
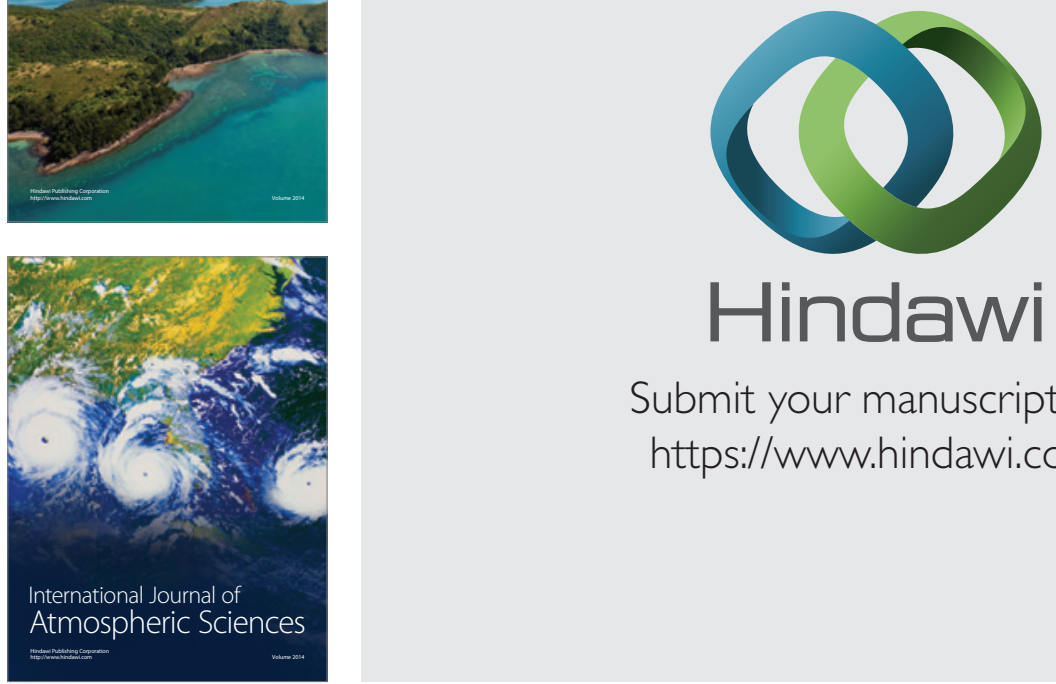

Submit your manuscripts at

https://www.hindawi.com
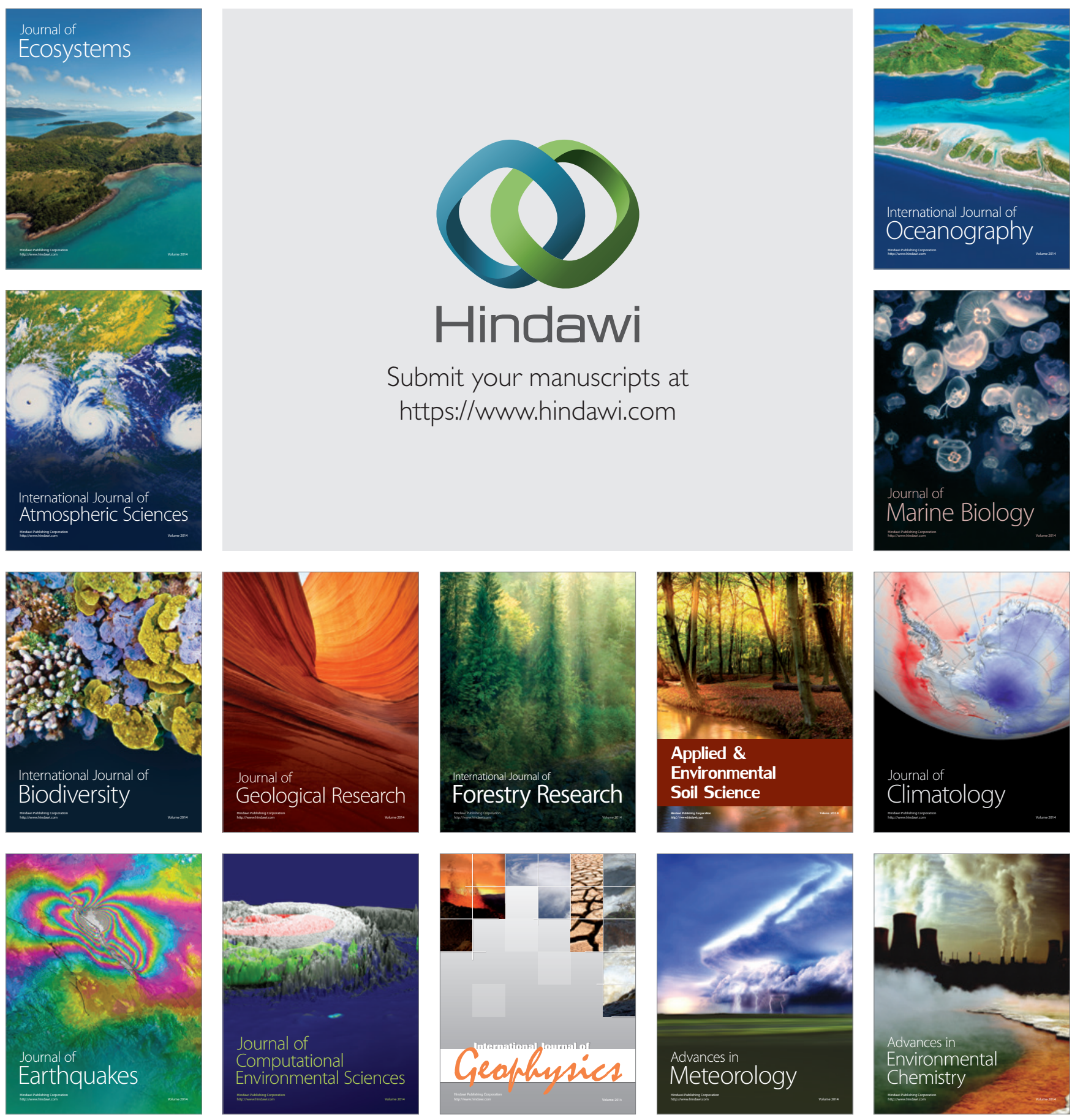